\title{
Simulated effects of a seasonal precipitation change on the vegetation in tropical Africa
}

\author{
E. S. Gritti ${ }^{1,2,3, *}$, C. Cassignat ${ }^{2, *}$, O. Flores ${ }^{1}$, R. Bonnefille ${ }^{2}$, F. Chalié ${ }^{2}$, J. Guiot ${ }^{2}$, and D. Jolly ${ }^{3}$ \\ ${ }^{1}$ CEFE, UMR 5175 CNRS/Université Montpellier II, 1919, route de Mende, 34293, Montpellier cedex 5, France \\ ${ }^{2}$ CEREGE, UMR 6635 CNRS/Aix-Marseille Université, Europôle Méditerranéen de l'Arbois BP80, 13545 Aix en \\ Provence cedex 4, France \\ ${ }^{3}$ ISEM, UMR 5554 CNRS/Université Montpellier II, Case 61, 34095 Montpellier cedex 5, France \\ *These authors contributed equally to the work
}

Received: 27 January 2009 - Published in Clim. Past Discuss.: 10 March 2009

Revised: 17 March 2010 - Accepted: 18 March 2010 - Published: 30 March 2010

\begin{abstract}
Pollen data collected in Africa at high (Kuruyange, valley swamp, Burundi) and low altitude (Victoria, lake, Uganda; Ngamakala, pond, Congo) showed that after $6 \mathrm{ky}$ before present (BP), pollen of deciduous trees increase their relative percentage, suggesting thus the reduction of the annual amount of precipitation and/or an increase of in the length of the dry season. Until now, pollen-climate transfer functions only investigated mean annual precipitation, due to the absence of modern pollen-assemblage analogs under diversified precipitation regimes. Hence these functions omit the potential effect of a change in precipitation seasonality modifying thus the length of the dry season. In the present study, we use an equilibrium biosphere model (i.e. BIOME3.5) to estimate the sensitivity of equatorial African vegetation, at specific sites, to such changes. Climatic scenarios, differing only in the monthly distribution of the current annual amount of precipitation, are examined at the above three locations in equatorial Africa. Soil characteristics, monthly temperatures and cloudiness are kept constant at their present-day values. Good agreement is shown between model simulations and current biomes assemblages, as inferred from pollen data. To date, the increase of the deciduous forest component in the palaeodata around $6 \mathrm{ky} \mathrm{BP}$ has been interpreted as the beginning of a drier climate period. However, our results demonstrate that a change in the seasonal distribution of precipitation could also induce the observed changes in vegetation types. This study confirms the importance of taking into account seasonal changes in the hydrological balance. Palaeoecologists can greatly benefit from the use of dynamic process based vegetation mod-
\end{abstract}

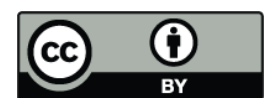

Correspondence to: E. S. Gritti (emmanuel.gritti@cefe.cnrs.fr) els to acccount for modification of the length of the dry season when they wish to reconstruct vegetation composition or to infer quantitative climate parameters, such as temperature and precipitation, from pollen or vegetation proxy.

\section{Introduction}

One of the fundamental assumptions in plant ecology is that, on continental or global scales, the distribution and composition of vegetation is strongly controlled by climatic conditions (Woodward, 1987; Stephenson, 1990) through the key processes of photosynthesis, respiration and transpiration. The length of the dry season has often been emphasized as a major control of vegetation structure and patterns in the tropics (Thomas, 1973; Box and Fujiwara, 2005; Vincens et al., 2007; Ngomanda et al., 2009). However, the relation between vegetation composition and climate is often described in a simple way using annual descriptors such as temperature and precipitation (Bonnefille et al., 1990). Yet, precipitation regimes are characterised by two main aspects (i.e. annual mean and month to month variability) modifying the duration and the intensity of the dry season(s) which have to be considered in defining the suitable bioclimatic limits of a vegetation type (Street-Perrott and Perrott, 1993). The modern mega-climate of Africa is quite simple due to the simple topography of the continent. Climatic zones related to the upper-level circulation tend to occur as symmetrical belts on either side of the equator (Thompson, 1965). Consequently two symmetric gradients of temperature and humidity spread from the equator. The tropical climate is governed by the seasonal movement of the meteorological equator (i.e. intertropical convergence zone, ITCZ) in response to changes in

Published by Copernicus Publications on behalf of the European Geosciences Union. 
the location of maximum solar heating. The ITCZ migrates northward to ca. $15-24^{\circ} \mathrm{N}$ in June to August, and southward to ca. $8^{\circ} \mathrm{N}$ in West Africa and to ca. $16^{\circ} \mathrm{S}$ in East Africa in December and February, respectively (Hastenrath, 1988). The equatorial zone is therefore characterized by a double rainfall maximum. In East Africa, the altitudinal effect on climate associated with the local topography (Mt Kenya, 5197 m; Mt Ruwenzori, 5120 m; Kilimandjaro, 5899 m; Mt Rungwe, $3176 \mathrm{~m}$ ) is superimposed to this simple pattern and results in a decrease of the temperature with altitude associated with a complex distribution of rainfall (Osmaston, 1989). During the period between $12 \mathrm{ky} \mathrm{BP}$ and $6 \mathrm{ky} \mathrm{BP}$, the insolation had a higher seasonal contrast compared to present day values due to solar radiation changes associated with orbital parameter development (Kutzbach and Street-Perrott, 1985) thus inducing some changes in the seasonal pattern of the precipitation at regional scale. The COHMAP modelling project (Kutzbach et al., 1993) simulated higher July precipitation across a part of Africa due to the intensification of the summer monsoon. For instance, within the intertropical belt in Africa at $12 \mathrm{ky} \mathrm{BP}$ (respectively $6 \mathrm{ky} \mathrm{BP}$ ), simulations show an increase of the July precipitation of ca. $4 \mathrm{~mm}$ day $^{-1}$ (respectively ca. $2 \mathrm{~mm} \mathrm{day}^{-1}$ ). However, in the equatorial highlands of central East Africa during the early Holocene (10-7 ky BP), the reconstructed mean annual precipitation is $30 \mathrm{~mm} \mathrm{yr}^{-1}(-2 \%)$ below present-day value with several positive shifts (Bonnefille and Chalié, 2000). Moreover, pollen records show large variations of vegetation during the Holocene as a consequence of precipitation changes (Bonnefille et al., 1990; Vincens et al., 1993). Until recently, most studies estimated the annual precipitation from palaeodata (Bonnefille et al., 1990; Vincens et al., 1993; Peyron et al., 2000). It has been shown (Barboni et al., 2003) that the seasonality of the precipitation (as represented by the duration of the dry season) in the tropical region of South West India has a strong impact on the modern pollen taxa distribution. The first attempts to estimate the total duration of the rainy season(s) by transfer functions (Chalié, 1992) need to be improved. Indeed, using pollen data does not allow us to unambiguously reconstruct environmental conditions much different from the modern ones, particularly when low atmospheric $\mathrm{CO}_{2}$ concentration prevail, because the reconstructions are ultimately based on the best analogues available within modern data (Guiot, 1990). One way to slacken this constraint is to use mechanistic models to simulate present and past vegetation distributions. This type of models describes explicitly photosynthetic processes and hydrological cycles according to empirical laws and experimental measurements. In this paper, we focus on the mean monthly precipitation using different scenario for this parameter to test its impacts on equatorial African ecosystems at the century time scale. For such time scales, vegetation and climate can be considered as being in steady state equilibrium (Webb, 1986). Therefore, changes in vegetation composition, in response to a modification of the precipitation regime (through the modification of the length of the dry season holding temperatures and $\mathrm{CO}_{2}$ level constant), may be evaluated with the equilibrium biosphere model BIOME3.5 (Haxeltine and Prentice, 1996). This model is applied at three sites along an equatorial transect, in different botanical contexts in order to simulate a set of diversified ecosystem responses. The three selected sites show consistent pollen records of past vegetation. They all show a tropical forest established at the beginning of the Holocene, and taxonomic changes during the mid-Holocene that have been interpreted as a consequence of hydrologic changes (annual rainfall amount and/or seasonal precipitation change) (Kendall, 1969; Elenga et al., 1994; Jolly et al., 1994).

\section{Methods}

\subsection{BIOME3.5}

BIOME3.5 is a modified version of the BIOME3 terrestrial biosphere model (Haxeltine and Prentice, 1996) including improved descriptions of competition, phenology, photosynthesis and respiration (Kaplan et al., 2002). This model describes the potential vegetation present at a site following an essential logic. First, the model selects the plant functional types (PFTs, assemblage of species which have the same response to environmental factors) likely to be present on the site according to their physiological, phenological and bioclimatic characteristics and the site specific climatic conditions. For each of the selected PFTs, maximum sustainable leaf area index (LAI) and net primary production (NPP), are calculated using a coupled carbon and water flux model. NPP values are then compared independently for trees and grasses to select the dominant PFT. Simulation of competition between trees and grass is based on NPP and LAI values. Vegetation is described as monthly/annual values of LAI and NPP for the dominant PFT and secondary PFTs. These outputs can be classified into biome types according to the dominance and assemblages of PFTs and a classification scheme (Haxeltine and Prentice, 1996). Model inputs are expressed as latitude, atmospheric $\mathrm{CO}_{2}$ content, soil texture (Zobler and for Space Studies (1986); map of soil from the FAO-Unesco, 1974) and monthly mean values of temperature, precipitation and cloudiness. BIOME3.5 is similar to the latest version BIOME4 (Kaplan et al., 2002) in its representation of tropical vegetation. We used BIOME3.5 for comparison with Guiot et al. (2000).

\subsection{Validation of BIOME3.5}

A qualitative and quantitative comparison at global scale of the BIOME3 simulations of the present-day vegetation with a digitised global map of potential natural vegetation showed that the model successfully reproduces the broad scale pattern (Haxeltine and Prentice, 1996). Another comparison 


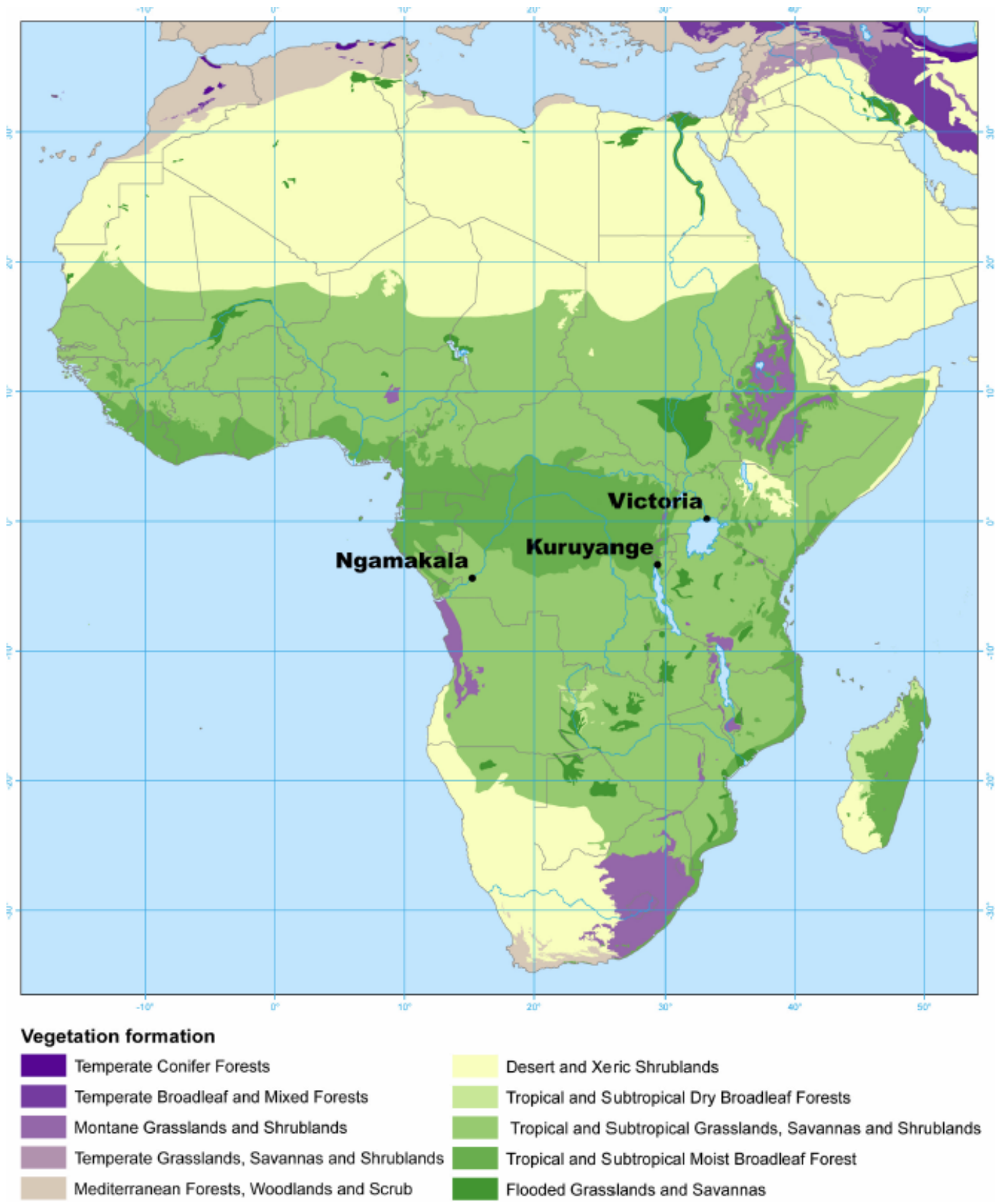

Fig. 1. Sites location and current observed vegetation formations.

made between predicted NPP and a set of NPP data measured by Leith (1975) showed a fair agreement between the predicted NPP and measured NPP, yielding a correlation coefficient of 0.74 (Haxeltine and Prentice, 1996). However, even if BIOME3 can be considered robust in the intertropical area (Jolly and Haxeltine, 1997), it tends to underestimate the absolute NPP values above $1100 \mathrm{gC} \mathrm{m}^{-2} \mathrm{yr}^{-1}$ The same bias has been observed for a large number of other global NPP models (Moore III et al., 1995). BIOME3.5 was not changed for the intertropical biomes.

\subsection{Sites description}

The selected sites are located on an African equatorial transect (Fig. 1) characterised by constant temperatures during the year (Fig. 2). We chose Ngamakala (Congo, $4^{\circ} 4^{\prime} \mathrm{S}$, $15^{\circ} 23^{\prime} \mathrm{E}, 400 \mathrm{~m}$; Elenga et al., 1994), Victoria (Pilkinton bay, Uganda, $0^{\circ} 19^{\prime} \mathrm{N}, 33^{\circ} 20^{\prime} \mathrm{E}, 1134 \mathrm{~m}$; Kendall, 1969) and Kuruyange (Burundi, $3^{\circ} 35^{\prime}$ S, $29^{\circ} 41^{\prime}$ E 2000 m; Bonnefille et al., 1991; Jolly and Bonnefille, 1991; Jolly et al., 1994). The three sites present high values of annual 

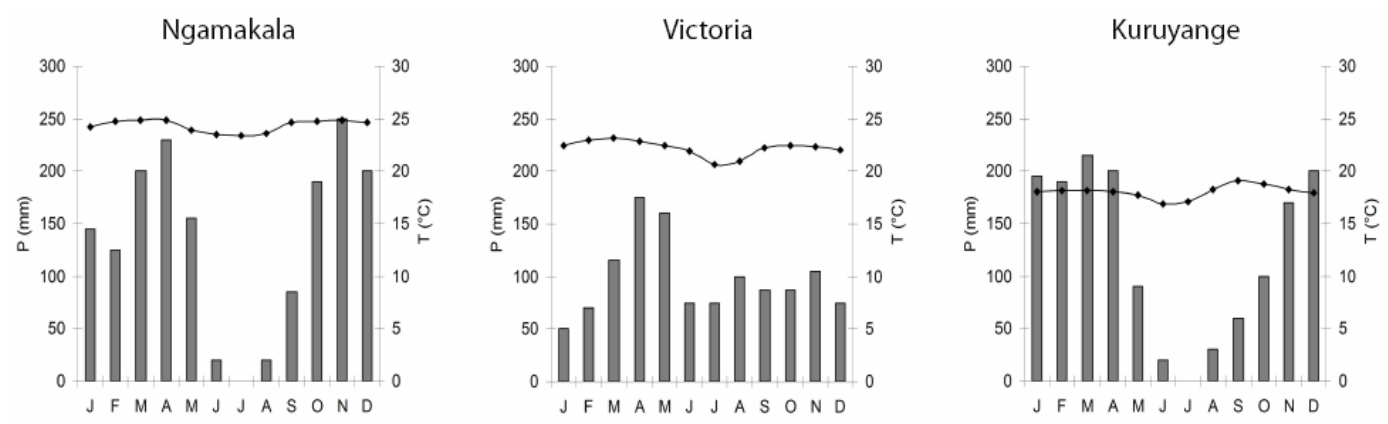

Fig. 2. Current mean monthly temperatures (lines) and precipitation (bars) distribution for the three studied sites (Leemans and Cramer, 1991).

precipitation and annual mean temperature (Ngamakala: $1620 \mathrm{~mm}, 24.1^{\circ} \mathrm{C}$; Victoria: $1175 \mathrm{~mm}, 22.3^{\circ} \mathrm{C}$; Kuruyange: $1470 \mathrm{~mm}, 17.4^{\circ} \mathrm{C}$ ) which are considered as non limiting conditions for the current vegetation composition. These sites presents, respectively mean dry-seasons of 84,3 and 96 consecutives dry days according to the climatic database (Leemans and Cramer, 1991).

According to White (1983), Ngamakala present-day vegetation belongs to the Guineo-Congolian domain. Kuruyange, a swamp today anthropised, is located in the afromontane domain with a mosaic of East African evergreen bushland and secondary Acacia wooded grassland near the transitional rain forest (White, 1983). The surrounding vegetation of Pilkington Bay is a mixed mosaic of semi-deciduous or deciduous forest and savanna.

\subsection{Climate data}

At each site, relevant climatic data are obtained by interpolation from a database of global climatic variables (Leemans and Cramer, 1991) using an artificial neural network (ANN), as performed in Africa by (Peyron et al., 2000).

Temperature, cloudiness and soil texture are maintained constant at their current site values in the simulations. It may appear unrealistic to change the precipitation distribution when keeping cloudiness constant. However, changes in cloudiness are difficult to estimate because co-variations between precipitation and cloudiness are poorly understood in this context (Gregory and Morris, 1996). Moreover, we aim at deciphering the ecosystem response to one specific parameter under investigation (rainfall seasonality), hence primarily producing sensitivity experiments rather than fully realistic experiments. Only the distribution and the magnitude of the monthly precipitation during the year are modified, keeping constant the annual amount of precipitation.

The construction of the precipitation scenarios can be described in three steps:
1. Automatic identification of the months with extreme precipitation (minimum or maximum) is done on the modern mean monthly precipitation distribution curve for each studied site.

2. The amount of precipitation for one of the extremes is set by increments of $20 \mathrm{~mm}$ from $-120 \mathrm{~mm}$ to $120 \mathrm{~mm}$. This step is a compromise between the number of scenarios and the calculation time. As the intertropical region is characterised by two wet seasons, the amount of precipitation is modified for the four extreme months.

3. The monthly amounts of precipitation for the months located between two extreme months are linearly interpolated as following:

$$
\Delta P(j)=\frac{\Delta P_{\mathrm{ex}}(2)-\Delta P_{\mathrm{ex}}(1)}{m_{\mathrm{ex}}(2)-m_{\mathrm{ex}}(1)} \times\left[m(j)-m_{\mathrm{ex}}(1)\right]+\Delta P_{\mathrm{ex}}
$$

where the extreme months encompassing month $m(j)$ are noted $m_{\mathrm{ex}}(1)$ and $m_{\mathrm{ex}}(2)$, their increments being $\Delta P_{\mathrm{ex}}(1)$ and $\Delta P_{\mathrm{ex}}(2) . \quad P(j)$ is the modern precipitation of month $j$ and $\Delta P(j)$ is its increment. For each of the 4 modified months, there are 12 possibilities to obtain a new distribution of precipitation. The new distribution must have an annual amount of precipitation more or less equal to those of the actual precipitation Pan on the site. Strictly, the new distribution $P^{\prime}$ an is such that $\mid P^{\prime}$ an $-P$ an $\mid<100 \mathrm{~mm}$ (Fig. 3). This strong constraint highly reduces the number of tested distributions: for example, when it is applied on the Ngamakala site, the number of simulated distributions is 5410 . Simulation of the vegetation is performed in each of the new precipitation scenario, using BIOME3.5.

\subsection{Variables selected to describe the vegetation change}

The NPP value of each PFT present in the grid cell is used to describe the vegetation. We express the seasonal precipitation signal with simple parameters (number of consecutives dry days, sum of the daily amount of precipitation). We use 


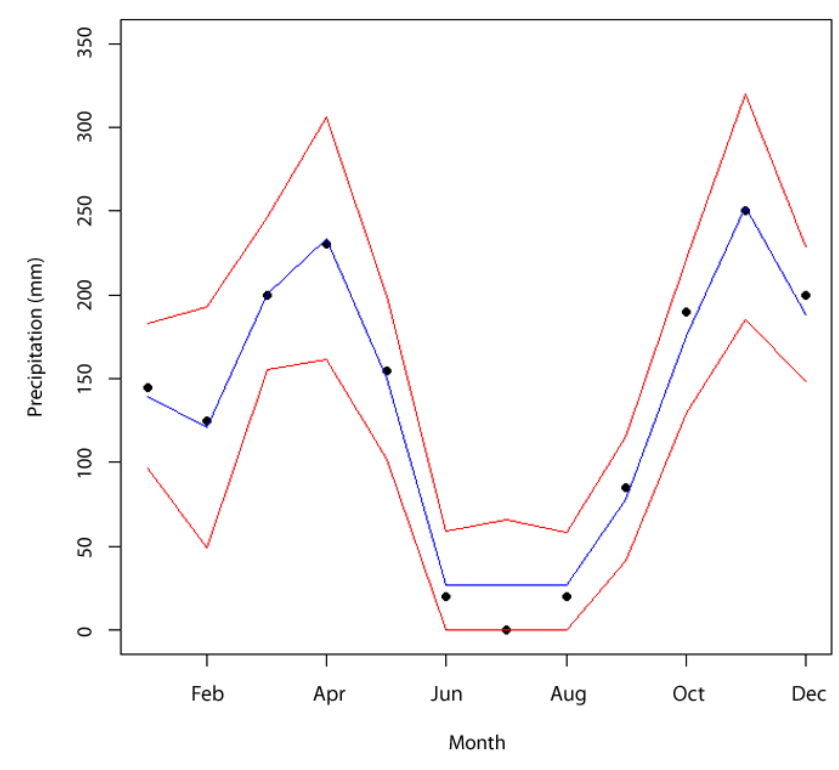

Fig. 3. Simulated distributions of precipitation at Ngamakala. Solid circle, current precipitation distribution according to the climatic database (Leemans and Cramer, 1991); Blue line, mean simulated distribution. Red lines, mean simulated distribution \pm SD.

the "highest number of consecutive dry days" as a discriminant variable. A month is defined as "dry" when the monthly amount of precipitation is lower than $30 \mathrm{~mm}$ (Köppen, 1884). This variable requires a daily time-step and is calculated by a linear interpolation:

- For a month $i$, the amount of precipitation $P\left(m_{i}\right)$ is attributed to the julian day representing the middle of the month $\left(m d_{i}\right)$ considered (Haxeltine and Prentice, 1996).

- For days between two consecutive mid-month days, precipitation at day $j+1$ is obtained from precipitation at day $j$ as follows:

$$
P_{j+1}=P_{j}+\frac{P\left(m_{i+1}\right)-P\left(m_{i}\right)}{\left(m d_{i+1}-m d_{i}\right)^{2}}
$$

\subsection{Relationship between seasonality and biome}

The biome types at each of the three sites are simulated for each of the precipitation scenarios defined as explained above. The length of the dry season is given by the number of consecutive dry days. We deduce, for each biome type, the range of dry season length and the percentage of appearance of each biome type related to the total number of simulations for this range (frequency of occurence of the biome in $\%$ ). Simulated biome type can be classified by increasing dry season length (Fig. 4) as follows:

- Tropical Evergreen Forest: TrEF

- Tropical Semi-Deciduous Forest: TrsDF
- Tropical Deciduous Forest/ Woodland: TrDF/W

- Tropical Savanna: TrSa

The biomes TrEF, TrsDF and TrDF/W are all dominated by the "tropical raingreen trees" PFT. In this specific case, the biome selection is made according to the number of "greendays", i.e. the number of days when a foliage cover is present as a function of the Leaf Area Index of the dominant PFT.

\subsection{Altitudinal effect}

In addition, we evaluate the impact of the atmospheric pressure decrease at higher altitude, on vegetation composition simulated by Biome3.5. With a decrease of the atmospheric pressure, $\mathrm{CO}_{2}$ and $\mathrm{O}_{2}$ partial pressure also decrease in proportion modifying thus the altitudinal photosynthetic rate. We aim at testing how this lower atmospheric pressure leading in lower $\mathrm{CO}_{2}$ and $\mathrm{O}_{2}$ partitial pressure may change the vegetation response and sensitivity to a same seasonal variation in the precipitation distribution. At Kuruyange ( $2000 \mathrm{~m})$, in addition to seasonal changes in precipitation, we apply two distinct atmospheric pressures in our simulations: (1) sealevel atmospheric pressure and (2) $2000 \mathrm{~m}$ atmospheric pressure. Estimates of the atmospheric pressure are calculated according to an empirical relationship (Triplet and Roche, 1977) as following:

$P(z)=P\left(z_{0}\right)-0.08 z$

with $P$ representing the atmospheric pressure (in $\mathrm{hPa}$ ), $z$, the altitude (in $\mathrm{m}$ ), and $P\left(z_{0}\right) \approx 1000 \mathrm{hPa}$ being the atmospheric pressure at the sea level.

\section{Results}

Under the current precipitation distribution, at each of the three sites the simulated biome is TrsDF, a mixed forest characterised by evergreen and deciduous trees. When we modify the precipitation regime according to the rules given above, four types of biomes are simulated but with varying frequencies (Fig. 4). At Ngamakala, the modern biome TrsDF is the most frequent $(60 \%$ of the total number of simulated biome), followed by the drier TrDF/W (37\%). For Victoria, the most frequent biome is drier than the modern one (65\% TrDF/W), the modern biome TrsDF being the second in frequency $(32 \%)$. For Kuruyange, the vegetation has a particularly strong response to variations of precipitation seasonality. Indeed, the modern biome type is TrsDF dominant (45\%) but two other types are important: a wetter biome $\mathrm{TrEF}(32 \%)$ and a drier one TrDF/W (23\%). PFTs potentially present at each site are of three types: tropical raingreen trees (trt), tropical/warm or temperate grass (trg/teg) and woody desert plant type $\mathrm{C}_{3}$ and $\mathrm{C}_{4}$ (wod). At Kuruyange, teg replaces trg. Generally, the dominant PFT is trt whatever the chosen site, except some rare cases where it is trg. 


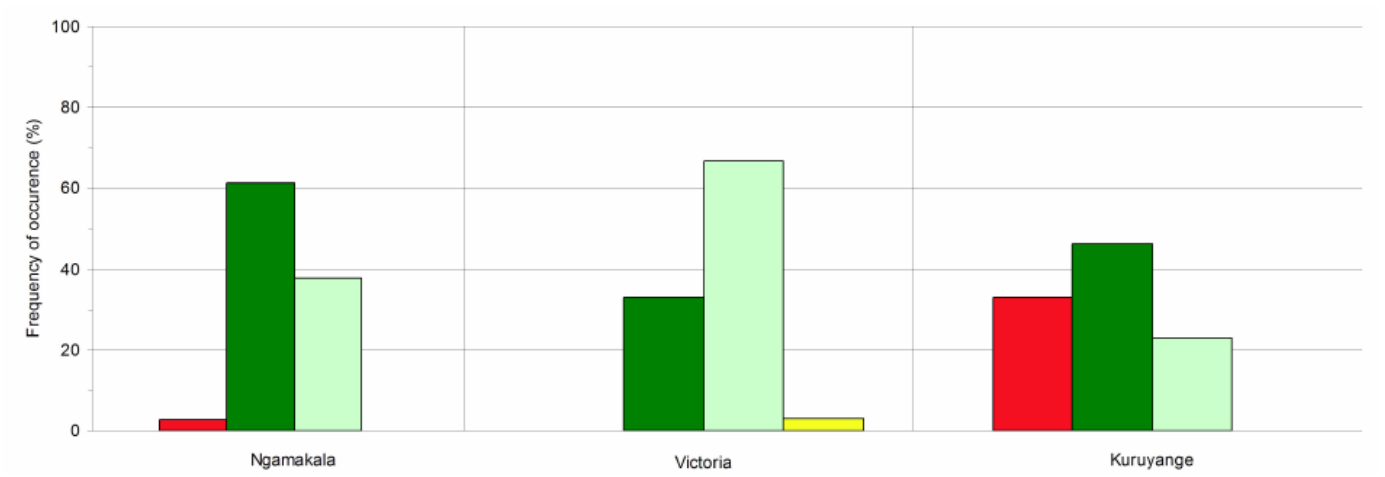

Fig. 4. Frequency of occurence within the total number of simulations of the biome types simulated for each site. In red, Tropical Evergreen Forest biome; In dark green, Tropical Semi-Deciduous Forest biome; In light green, Tropical Deciduous Forest/Woodland biome; In yellow, Tropical Savanna.

Figure 5 gives the value of NPP of the three PFTs for the Ngamakala site as a function of the number of consecutives dry days, each point representing one scenario of precipitation. It is noticeable that NPP values vary more in function of the PFT and vary less and differently in function of the driest-season variable. The trt PFT has a NPP value decreasing from $2000 \mathrm{gC} \mathrm{m}^{-2} \mathrm{yr}^{-1}$ to $1400 \mathrm{gC} \mathrm{m}^{-2} \mathrm{yr}^{-1}$ for a driestseason longer than 100 days. For the trg PFT, the NPP values seem to be almost constant and equal to $1800 \mathrm{gC} \mathrm{m}^{-2} \mathrm{yr}^{-1}$, despite a small discontinuity around 40 days. The dispersion of the NPP values is related to the number of significatively different scenarios considered for each value of the driestseason variables.

Figure 6a represents the frequency of appearance of each biome type as a function of the number of consecutives dry days for Ngamakala. Our results show two distinct transitions, but the first is less marked than the second. Between 20 and 100 consecutives dry days, the probability of simulating a semi-deciduous biome is almost equal to one. As the number of dry days increases above 100 days, the probability of simulating a deciduous biome reaches a maximum. Note that the shift between TrsDF and TrDF/W biomes is simulated as a fairly radical change, simulated strictly for a driest season between 100 and 120 days. For this site, the savanna biome type rarely occurs. At Victoria, only one transition occurs between a semi-deciduous forest and a deciduous one (Fig. 6b). This transition takes place between 60 and 100 dry days and reveals progressive, especially if compared to the change observed in Ngamakala. The tropical savanna is also simulated, but its occurrence is always low.

At Kuruyange, located at $2000 \mathrm{~m}$, BIOME3.5 simulates two distinct transitions (Fig. 6c). Between 0 to 100 consecutives dry days, the model simulates an evergreen forest if we don't take reduced atmospheric pressure into account. Afterwards, the biome type is semi-deciduous until 140 dry days. Finally, the frequency of the deciduous forest is high above 140 dry days. We notice that the range of consecutives dry

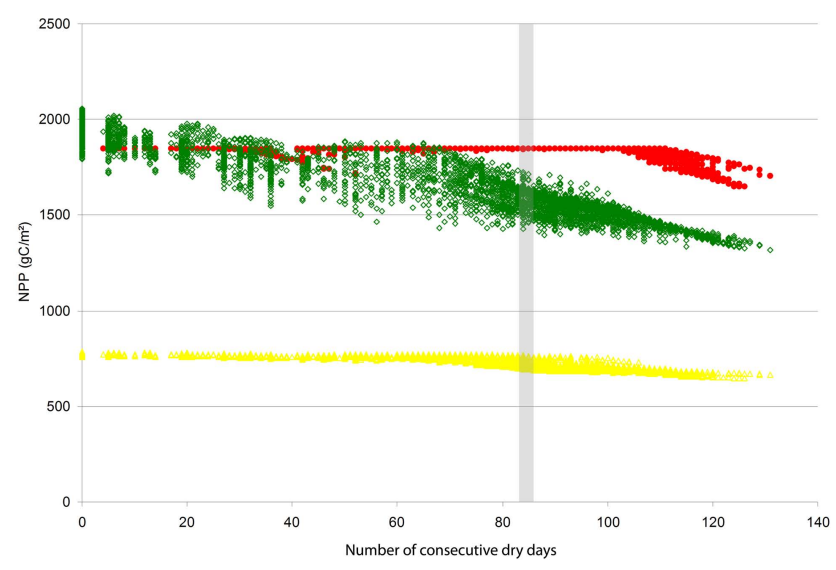

Fig. 5. Evolution of the NPP of 3 PFTs, as a function of the number of consecutives dry days for Ngamakala $(400 \mathrm{~m})$. In red, tropical/warm grass PFT (trg); In green, tropical raingreen trees PFT (trt); In yellow, woody desert plant type C3 and C4 PFT (wod). In grey, current number of consecutive dry days according to the climatic database (Leemans and Cramer, 1991).

days within which the semi deciduous biome dominates is rather narrow. The results are significantly different when we take into account the decrease of pressure with elevation (Fig. 6d). The number of consecutives dry days within which the present-day biome at Kuruyange occurs increases from days $100-140$ to days $40-120$. Moreover, both biome transitions occur at lower critical values of number of consecutives dry days.

\section{Discussion}

Under water stress, the model predicts that all PFTs undergo a general decrease of their respective NPP values. A first question to ask is whether the simulated physiological response is realistic. In term of absolute NPP, BIOME3.5 
A) Ngamakala

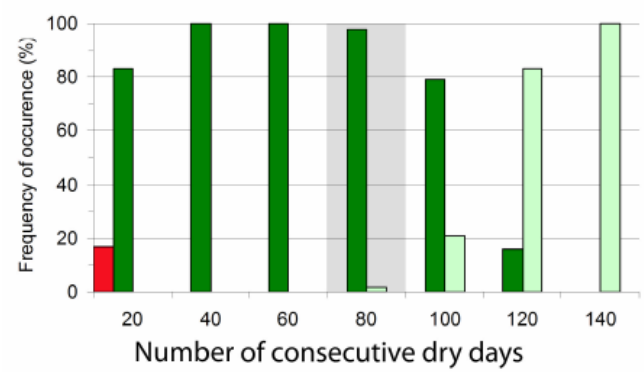

B) Victoria

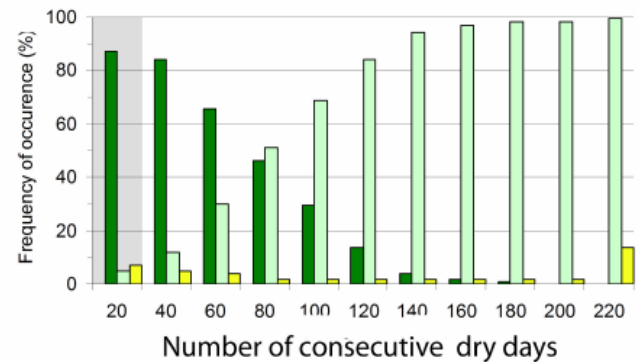

C) Kuruyange (sea level)

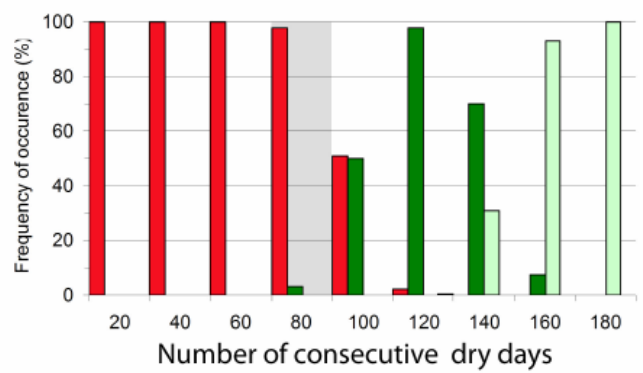

D) Kuruyange (2000 m)

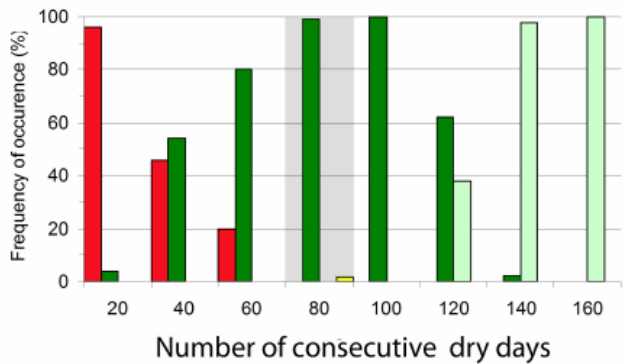

Fig. 6. Frequency of occurence by class of number of consecutives dry days of the Biome types simulated for each site. In red, Tropical Evergreen Forest biome; in dark green, Tropical Semi-Deciduous Forest biome; in light green, Tropical Deciduous Forest/Woodland biome; in yellow, Tropical Savanna for (A) Ngamakala (Congo), (B) Victoria (Uganda), (C) Kuruyange (Burundi) with atmospheric pressure measured at the sea level and Kuruyange (Burundi), (D) with atmospheric pressure at $2000 \mathrm{~m}$, calculated applying an empirical correction to take into account the altitudinal effect. In grey, current number of consecutive dry days according to the climatic database (Leemans and Cramer, 1991).

underestimates systematically the ecosystem NPP above $1000 \mathrm{gC} \mathrm{m}^{-2} \mathrm{yr}^{-1}$ (Haxeltine and Prentice, 1996). However, due to the process-based characteristics of the model, we believe that the simulated response in terms of trend is realistic. All the PFTs are stressed (marked by a general decrease of the mean NPP value above a PFT-specific threshold) by an increase of the dry season length. The differential response illustrates that grasses have a better adaptation capacity to water stress than woody plants. These differences could be interpreted by a different growth scheme for plants corresponding to these two PFTs, with a "short" longevity (i.e., a better yield for a broad climatic spectrum) for grass type.

Studies on the effect of the atmospheric $\left(\mathrm{CO}_{2}\right)$ show that $\mathrm{C}_{3}$ natural and cultural plants decrease their photosynthetic rate when $\mathrm{CO}_{2}$ partial pressure is reduced (Bazzaz, 1990; Sage, 1995; Sage and Coleman, 2001), inducing a decrease of NPP. When we run BIOME3.5 with decreasing $\mathrm{CO}_{2}$ partial pressure (increasing altitude), we observe displacement of the transition between biomes mainly due to an overall decrease in both NPP and Leaf Area Index values (i.e. foliage covers). This result is well in agreement with previous studies (see Friend and Woodward, 1990). However, Biome3.5 lacks explicite description of the effect of the lowered partial pressure of $\mathrm{O}_{2}$ on photosynthesis through the reduction in the rate of photorespiration (Woodward, 1986). Similarly,the modification with elevation of $\mathrm{CO}_{2}$ diffusion coefficient (Terashima et al., 1995) as well as light intensity and greater evaporative demand (Smith and Geller, 1979) may counterbalance these results. In BIOME3.5, until now, the present PFTs are selected using climatic constraints without taking into account the altitudinal effect on $\mathrm{CO}_{2}$ partial pressure. Therefore, to improve vegetation simulation, it would be better to select potentially present PFT(s) after NPP and LAI calculations which would take this effect into account. At the biome level, ecosystem transitions are simulated as a function of the driest season length. These transitions are characterised by vegetation composition modification from a tropical semi-deciduous forest biome to a tropical deciduous forest biome. At present-day, BIOME3.5 simulates a semi-deciduous forest at the three studied sites with a length of the driest season of 3,84 and 96 days at Victoria, Ngamakala and Kuruyange, respectively. This study shows that even if we keep constant the total annual amount of precipitation, a seasonal change is able to produce major biome changes. The change toward drier biomes, respectively appears around 110, 80 and 100/150 days, respectively, of driest season at Ngamakala, Victoria and Kuruyange without altitude effect. We note that the simulated vegetation change 
due only to the change of the seasonality of precipitation is more important than the changes observed in the palaeodata during the Holocene at the three sites (Kendall, 1969; Bonnefille et al., 1991; Elenga et al., 1994; Jolly et al., 1994). Our simulations demonstrate that we have to take into account the seasonal distribution of precipitation when reconstructing past climates. Reconstruction of mean annual climatic variables (Bonnefille et al., 1990; Peyron et al., 2000; Bonnefille and Chalié, 2000; Peyron et al., 2006) in tropical areas must be completed by considering the precipitation seasonal distribution. If BIOME3.5 output correctly matches palaeodata, the next step will consist in developing an objective and automatic procedure to determine which climatic scenario are the most reliable. Regarding the threshold on the monthly amount of precipitation to define a dry month, the literature is abundant. The value of $30 \mathrm{~mm}$ used here is perhaps the oldest definition of a dry month (Köppen, 1884) and, according to Aubréville and Chevalier (1949), $30 \mathrm{~mm}$ is "certainly under the true value, but this corresponds to a certainty". The calculation of the number of dry days could be improved by using the xerothermic Gaussen index (Gaussen and Bagnouls, 1953) which takes into account the relative air humidity. Moreover, while the processes considered in biospheric models are highly nonlinear, some of them have characteristic times substantially shorter than one month. The use of monthly average data as model forcing is thus not a priori justified and may lead to non-negligible errors on the model output variables (Hubert et al., 1998). The use of processesbased ecosystem models has already been shown to be a powerful strategy to perform climate reconstruction from palaeodata (Prentice and Harrison, 2009). Yet, the model used in this study is an equilibrium biosphere processes-based model not simulating explicitly disturbances such as fire disturbance or human land management which are largely controlling the trees/grasses balance in disturbance-prone ecosystems (van Langevelde et al., 2003; Gritti et al., 2006).Thus, further studies on past climatic reconstruction from palaeorecords would greatly benefit from the use of new generation of explicit processed-based dynamic vegetation models.

\section{Conclusions}

The effect of a seasonal change in the seasonality distribution of precipitation on the vegetation has been tested with an equilibrium vegetation model. Our simulations confirm that at all sites, located near the Equator, a substantial increase of the number of consecutives dry days could easily lead to a change in the tropical forest composition and structure such as those observed in the pollen diagrams during the Holocene. The impact on the vegetation depends on the PFT and the location. A smooth seasonal change in the precipitation as used in this study can induce one or several well marked biome transition. The change toward a drier biome, i.e. from a semi-deciduous to a deciduous one for instance, appears, respectively at 110, 80 and 150 days of driest season at Ngamakala, Victoria and Kuruyange. The NPP value of each PFT potentially present at the tropical location is affected by the seasonality of precipitation.

Finally, our study indicates that in the future, sensitivity analyses of models will be very useful to test explicit or often implicit hypotheses assumed by palaeoecologists. Here, without a modelling approach it would be impossible to estimate the potential impact of a change in the seasonality of the precipitation at a specified location. In natural conditions, it is rare to find exact analogues (same mean annual temperature, annual precipitation, soil, altitude, latitude,...) with only a change in the precipitation distribution. This lack of analogues allows for the common assumption by palaeoclimatologists that a change of vegetation is only due to a change of the annual amount of precipitation. Our study demonstrates the importance of seasonal distribution of precipitation in pollen-derived climate reconstructions. A way to integrate such changes is the inverse modelling iterative procedure developed by Guiot et al. $(1999,2000)$ and extensively applied to Africa by Wu et al. (2007a,b).

Acknowledgements. We are grateful to A. Vincens, L. Dallari, G. Riollet, G. Buchet, and A. Fayolle for helpful discussions and to J. Kaplan who has provided the BIOME3.5 model. Pollen data have been provided by the contributors of the African Pollen Database. This research has been funded by the EC INCO programme [INCO-DC (DG XII ERB3514PL972473)]. This paper is also a contribution to project MOTIF (EVK2-CT-2002-00153) of the EU Environment and Sustainable Development Program. E. S. Gritti acknowledges support from the ANR founded project QDiv. We thank the referees for constructive comments on an earlier version of this paper.

Edited by: D.-D. Rousseau

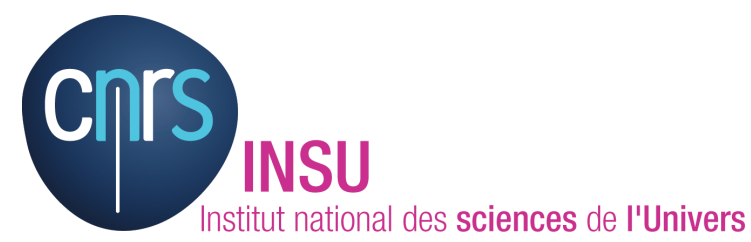

The publication of this article is financed by CNRS-INSU.

\section{References}

Aubréville, A. and Chevalier, A.: Climats, forêts et désertification de l'Afrique tropicale, Société d'éditions géographiques, maritimes et coloniales, 1949.

Barboni, D., Bonnefille, R., Prasad, S., and Ramesh, B.: Variation in modern pollen from tropical evergreen forests and the monsoon seasonality gradient in SW India, J. Veg. Sci., 14, 551-562, 2003.

Bazzaz,F.A.: The response of natural ecosystems to the rising global CO2 levels, Annu. Rev. Ecol. Syst., 21, 167-196, 1990. 
Bonnefille, R. and Chalié, F.: Pollen-inferred precipitation timeseries from equatorial mountains, Africa, the last $40 \mathrm{kyr} \mathrm{BP}$, Global Planet. Change, 26, 25-50, 2000.

Bonnefille, R., Roeland, J. C., and Guiot, J.: Temperature and rainfall estimates for the past 40000 years in equatorial Africa, Nature, 346, 347-349, 1990.

Bonnefille, R., Riollet, G., and Buchet, G.: Nouvelle séquence pollinique d'une tourbiére de la crête Zaire-Nil (Burundi), Rev. Palaeobot. Palynol., 67, 315-330, 1991.

Box, E. O. and Fujiwara, K.: vegetation types and their broad-scale distribution, in: Vegetation Ecology, Wiley-Blackwell, 106-128, 2005.

Canadell, J., Jackson, R. B., Ehleringer, J. B., Mooney, H. A., Sala, O. E., and Schulze, E. D.: Maximum rooting depth of vegetation types at the global scale, Oecol., 108, 583-595, 1996.

Chalié, F.: Paleoclimatologie quantitative en Afrique orientale depuis 40000 ans, Pollen et Statistiques, Ph. D. thesis, Marseille, University of Aix-Marseille III, 160 pp., 1992.

Elenga, H., Schwartz, D., and Vincens, A.: Pollen evidence of late Quaternary vegetation and inferred climate changes in Congo, Palaeogeogr., Palaeoclimatol., Palaeoecol., 109, 345-356, 1994.

FAO-Unesco: Soil Map of the World (1:5,000,000), 1, Legend, Unesco, Paris, France, 1974.

Friend, A .D. and Woodward, F. I.: Evolutionary and ecophysiological responses of mountain plants to the growing season environment, Adv. Ecol. Res., 20, 59-124, 1990.

Gaussen, H. and Bagnouls, F.: Saison sèche et indice xérothermique, Bull Soc Sci Nat Toulouse, 61, 193-239, 1953.

Gregory, D. and Morris, D.: The sensitivity of climate simulations to the specification of mixed phase clouds, Clim. Dynam., 12, 641-651, 1996.

Gritti, E. S., Smith, B., and Sykes, M. T.: Vulnerabilty of Mediterranean Basin ecosystems to climate change and invasion by exotic plant species, J. Biogeogr., 33, 145-157, 2006.

Guiot, J.: Methodology of the last climatic cycle reconstruction in France from pollen data, Palaeogeogr., Palaeoclimatol., Palaeoecol., 80, 49-69, 1990.

Guiot, J., Torre, F., Cheddadi, R., Peyron, O., Tarasov, P., Jolly, D., and Kaplan, J.: The climate of the Mediterranean Basin and of Eurasia of the last glacial maximum as reconstructed by inverse vegetation modelling and pollen data, Ecol. Mediter., 25, 193204, 1999.

Guiot, J., Torre, F., Jolly, D., Peyron, O., Boreux, J. J., and Cheddadi, R.: Inverse vegetation modeling by Monte Carlo sampling to reconstruct palaeoclimates under changed precipitation seasonality and $\mathrm{CO} 2$ conditions: application to glacial climate in Mediterranean region, Ecol. Modell., 127, 119-140, 2000.

HAstenrath, S.: Climate and circulation of the tropics, Reidel, Dordrecht, Boston, Lancaster, Tokyo, 455 pp., 1988.

Haxeltine, A. and Prentice, I.: BIOME3: An equilibrium terrestrial biosphere model based on ecophysiological constraints, availability, and competition among plant functional types, Global Biogeochem. Cy., 10, 693-709, 1996.

Hubert, B., Francois, L., Warnant, P., and Strivay, D.: Stochastic generation of meteorological variables and effects on global models of water and carbon cycles in vegetation and soils, J. Hydrol., 212, 318-334, 1998.

Jolly, D. and Bonnefille, R.: Diagramme pollinique d'un sondage Holocène de la Kuruyange (Burundi, Afrique Centrale), The comparative in palynology; pollen morphology of the african palms/Ballouche, A. éd; Maley, Jean. éd (Palaeoecology of Africa and the surrounding islands, 22), 22, 265-274, 1991.

Jolly, D. and Haxeltine, A.: Effect of Low Glacial Atmospheric CO2 on Tropical African Montane Vegetation, Science, 276, 786-788, 1997.

Jolly, D., Bonnefille, R., and Roux, M.: Numerical interpretation of a high resolution Holocene pollen record from Burundi, Palaeogeogr., Palaeoclimatol., Palaeoecol., 109, 357-370, 1994.

Kaplan, J. O., Prentice, I. C., and Buchmann, N.: The stable carbon isotope composition of the terrestrial biosphere: Modeling at scales from the leaf to the globe, Global Biogeochem. Cy., 16, 1-11, doi:10.1029/2001GB001403, 2002.

Kendall, R. L.: An ecological history of the lake Victoria basin, Ecol. Monog., 39, 121-176, 1969.

Köppen, W.: Die Warmezonen der Erde, nach der Dauer der Heissen, Gemassigten und Kalten Zeit und nach der Wirkung der Warme auf die Organische Welt Betrachtet, Meteorol. Z., 1, 215226, 1884.

Kutzbach, J. E. and Street-Perrott, F. A.: Milankovitch forcing of fluctuations in the level of tropical lakes from 18 to $0 \mathrm{kyrBP}$, Nature, 317, 130-134, 1985.

Kutzbach, J. E., Guetter, P. J., Behling, P. J., and Selin, R.: Simulated climatic changes: results of the COHMAP climate-model experiments, Global Climates Since the Last Glacial Maximum, 24-93, 1993.

Leemans, R. and Cramer, W.: The IIASA climate database for mean monthly values of temperature, precipitation and cloudiness on a terrestrial grid, IRR-91-18, IIASA, Laxenburg, 1991.

Leith, H.: Primary productivity in ecosystems: comparative analysis of global patterns, in: Unifying Concepts in Ecology: Report of the Plenary Sessions of the First International Congress of Ecology, The Hague, The Netherlands, 8-14 September, 1974, edited by: van Dobben, W. H. n and Lowe-McConnell, R.H., 1975.

Moore III, B., Cramer, W., Rasool, I., Sahagian, D., and Steffen, W.: Participants in "POTSDAM 95" Global net primary productivity: report of the Potsdam 95 IGBP NPP Model Intercomparison Workshop (GAIM-DIS-GCTE) Potsdam, Germany, June 20-22, 1995, in: Abstracts, GAIM First Sci. Conf., 1995.

Ngomanda, A., Neumann, K., Schweiser, A. and Maley, J.: Seasonality change and the third millenium BP rainforest crissi in southern Cameroon (Central Africa), Quaternary Res., 71, 37318, 2009.

Osmaston, H.: Glaciers, glaciations and equilibrium line altitudes on the Ruwenzori, Quaternary and Environmental Research on East African Mountains, 31-104, 1989.

Peyron, O., Jolly, D., Bonnefille, R., Vincens, A., and Guiot, J.: Climate of East Africa $600014 \mathrm{C} \mathrm{Yr} \mathrm{BP}$ as Inferred from Pollen Data, Quaternary Res., 54, 90-101, 2000.

Peyron, O., Jolly, D., Braconnot, P., Bonnefille, R., Guiot, J., Wirrmann, D., and Chalié, F.: Quantitative reconstructions of annual rainfall in Africa 6000 years ago: Model-data comparison, J. Geophys. Res., 111, D24 110, doi:1029/2006JD007396, http: //www.agu.org/pubs/crossref/2006/2006JD007396.shtml, 2006.

Prentice, I. C. and Harrison, S. P.: Ecosystem effects of CO2 concentration: evidence from past climates, Clim. Past, 5, 297-307, 2009 , http://www.clim-past.net/5/297/2009/. 
Sage, R. F.: Was low atmospheric CO2 during the Pleistocene a limiting factor for the origin of agriculture?, Global Change Biol., 1, 93-106, 1995.

Sage, R. F. and Coleman, J. R.: Effects of low atmospheric $\mathrm{CO} 2$ on plants: more than a thing of the past, TRENDS in Plant Science, 6, 18-23, 2001.

Smith, W. K. and Geller, G. N.: Plant transpiration at high elevations: Theory, field measurments, and comparisons with desert plants, Oecologia, 41, 109-122, 1979.

Stephenson, N. L.: Climatic Control of Vegetation Distribution: The Role of the Water Balance, Am. Nat., 135, 649-670, 1990.

Street-Perrott, F. A. and Perrott, R. A.: Holocene vegetation, lake levels and climate of Africa, 318-356, University of Minnesota Press, Minneapolis, 1993.

Terashima, I., Masuzawa, T., Ohba, H. and Yokoi, Y.: Is photosynthetic supressed at higher elevations due to low $\mathrm{CO} 2$ pressure?, Ecology, 76, 2663-2668, 1995.

Thomas, M. F.: African environments, Taylor and Francis, 198 pp., 1973.

Thompson, B. W.: The Climate of Africa, Oxford University Press, 132 pp., 1965.

Triplet, J. P. and Roche, G.: Météorologie Générale, Paris: Ecole Nationale de la Météorologie, 1977.

van Langevelde, F., van de Vijver, C. A. D. M., Kumar, L., van de Koppel, J., de Ridder, N., van Andel, J., Skidmore, A. K., Hearne, J. W., Stroosnijder, L., Bond, W. J., Prins, H. H. T. and Rietkerk, M.: Effects of fire and herbivory on the stability of savanna ecosystems, Ecology, 84, 337-350, 2003.

Vincens, A., Chalié, F., Bonnefille, R., Guiot, J., and Tiercelin, J. J.: Pollen-derived rainfall and temperature estimates from Lake Tanganyika and their implication for Late Pleistocene water levels, Quaternary Res., 40, 343-350, 1993.
Vincens, A., Garcin, Y., and Buchet, G.: Influence of rainfall seasonalityon African lowland vegetation during the Late Quaternary: pollen evidence from Lake masoko, Tanzania, J. Biogeogr., 34, 1274-1288, 2007.

Webb, T.: Is vegetation in equilibrium with climate? How to interpret late-Quaternary pollen data, Plant Ecol., 67, 75-91, 1986.

White, F.: The vegetation of Africa: a descriptive memoir to accompany the UNESCO/AETFAT/UNSO vegetation map of Africa, Natural Resources Research, 20, 1-356, 1983.

Woodward, F. I.: Ecophysiological studies on the shrub Vaccinium myrtillus L. taken from a wide altitudinal range, Oecologia,70, 580-586, 1986.

Woodward, F. I.: Climate and Plant Distribution, Cambridge University Press, 174 pp., 1987.

Wu, H., Guiot, J., Brewer, S., and Guo, Z.: Climatic changes in Eurasia and Africa at the last glacial maximum and mid-Holocene: reconstruction from pollen data using inverse vegetation modelling, Clim. Dynam., 29 , 211-229, doi:10.1007/s00382-007-0231-3, http://dx.doi.org/10. 1007/s00382-007-0231-3, 2007a.

Wu, H., Guiot, J., Brewer, S., Guo, Z., and Peng, C.: Dominant factors controlling glacial and interglacial variations in the treeline elevation in tropical Africa, PNAS, 104, 9720-9724, doi: 10.1073/pnas.0610109104, http://www.pnas.org/content/104/23/ 9720.abstract, 2007b.

Zobler, L.: A World Soil File for Global Climate Modelling, NASA Technical Memorandum 87802, NASA Goddard Institute for Space Studies, New York, USA, 1986. 